\title{
Submilliamp Threshold InGaAs-GaAs Strained Layer Quantum-Well Laser
}

\author{
T. R. CHEN, L. ENG, B. ZHAO, Y. H. ZHUANG, S. SANDERS, H. MORKOC, FELLOW, IEEE, AND \\ AMNON YARIV, FELLOW, IEEE
}

\begin{abstract}
Strained layer InGaAs-GaAs single-quantum-well buried heterostructure lasers were fabricated by a hybrid molecular beam epitaxy and liquid phase epitaxy technique. Very low threshold currents, $2.4 \mathrm{~mA}$ for an uncoated laser $(L=425 \mu \mathrm{m})$ and $0.75 \mathrm{~mA}$ for a coated laser $(R \sim 0.9, L=198 \mu \mathrm{m})$, were obtained. A $3 \mathrm{~dB}$ modulation bandwidth of $7.6 \mathrm{GHz}$ was demonstrated at low bias current $(14 \mathrm{~mA})$.
\end{abstract}

\section{INTRODUCTION}

I nGaAs-GaAs strained layer quantum-well lasers have been the subject of considerable recent interest [1]-[8]. The strained layer structure offers a new degree of freedom for valence band engineering, resulting in a potentially lower threshold and wider modulation bandwidth compared with conventional lattice-matched material quantum-well lasers [9]-[13]. Theoretical analysis predicted a threshold current density as low as $43 \mathrm{~A} / \mathrm{cm}^{2}$ and a $3 \mathrm{~dB}$ cutoff frequency as high as $90 \mathrm{GHz}$ [11]. Broadarea threshold current density of $174 \mathrm{~A} / \mathrm{cm}^{2}$ and threshold current of $12 \mathrm{~mA}$ on a stripe laser structure were achieved [14]. A threshold current of less than $7 \mathrm{~mA}$ was demonstrated in buried heterostructure [15]. A high-power output in excess of $200 \mathrm{~mW}$ was reported in an array configuration [16]. A continuous wave (CW) operation life time exceeding $5000 \mathrm{~h}$ was reported [17], showing encouraging reliability. In addition to these attractive features, the wavelength of InGaAs-GaAs laser falls into the range of $\lambda \approx 1 \mu \mathrm{m}$ (from $\lambda=0.87 \mu \mathrm{m}[16]$ to $\lambda>1 \mu \mathrm{m}$ [15], e.g.), which fills up the wavelength gap between GaAlAs-GaAs and GaInAsP-InP lasers. This opens up potential applications in certain circumstances such as optical pumping of some rare-earth solid-state lasers [16]. However, the present stage of the laser performance is still far from the theoretical expectation, and the highspeed modulation experiment has not been reported so far.

In this paper, we report on the substantial reduction of the threshold current of InGaAs-GaAs lasers. High-speed modulation is demonstrated for the first time. CW threshold current as low as $2.4 \mathrm{~mA}$ (for an uncoated laser) and

Manuscript received October 27, 1989; revised February 21, 1990. This work was supported by the Defense Advanced Research Projects Agency and the Office of Naval Research. The work of S. Sanders was supported by a National Science Foundation Graduate Fellowship.

T. R. Chen and Y. H. Zhuang are with the University of Electronic Science and Technology, China.

L. Eng, B. Zhao, S. Sanders, and A. Yariv are with the Department of Applied Physics, 128-95, California Institute of Technology, Pasadena, CA 91125

IEEE Log Number 9035991
$0.75 \mathrm{~mA}$ (for a coated laser), and a $3 \mathrm{~dB}$ bandwidth of $7.6 \mathrm{GHz}$ were achieved. A systematic study of the device performance and some related material properties are presented.

In Section II, we introduce the procedures for material preparation and device fabrication. The performance of the lasers is summarized in Section III. In Section IV, we describe the effect of dielectrical coating on the laser performance. The high-frequency direct current modulation results are presented in Section V.

\section{Structure and Fabrication}

The laser used for this study is a buried heterostructure (BH) graded index separated confinement heterostructure (GRIN-SCH) single-quantum-well (SQW) strained layer (STL) InGaAs-GaAs laser. The fabrication of the laser involves two-step crystal growth. The GRINSCH-SQWSTL material was prepared by the molecular beam epitaxy (MBE) technique. The BH laser structure was accomplished by utilizing the liquid phase epitaxy (LPE) regrowth technique.

In the first step, a laser structure was grown on a GaAs (100) substrate tilted $4^{\circ}$ towards the (111) direction. The structure consists of $1 \mu \mathrm{m}$ GaAs buffer layer, $1.5 \mu \mathrm{m}$ $\mathrm{Al}_{x} \mathrm{Ga}_{1-x}$ As cladding layer $(x=0.5), 0.15 \mu \mathrm{m}$ GRIN region with $x=0.5 \rightarrow 0.2,40 \AA$ GaAs spacer, $50 \AA$ InGaAs quantum well, $40 \AA \mathrm{GaAs}$ spacer, $0.15 \mu \mathrm{m}$ GRIN region $(x=0.2 \rightarrow 0.5), 1.5 \mu \mathrm{m} \mathrm{Al}_{0.5} \mathrm{Ga}_{0.5} \mathrm{As}$ layer, and $2000 \AA$ GaAs cap layer. The MBE growth was carried out in a Riber $2300 \mathrm{R} \& \mathrm{D}$ system. The substrate temperature was held at $600^{\circ} \mathrm{C}$ for the $\mathrm{GaAs}$ buffer and cap layers, $720^{\circ} \mathrm{C}$ in the cladding and graded regions, and ramped down during the GaAs spacer growth to about $620^{\circ} \mathrm{C}$ for the InGaAs quantum well. The temperatures quoted are obtained pyrometer readings. To accomplish the large substrate temperature differences necessary for high-quality AlGaAs and InGaAs growths, we have used an indium-free mounting technique thereby reducing the thermal mass of the sample and allowing for continuous growth without interruption. The indium mole fraction in the InGaAs quantum well is estimated to be larger than $35 \%$ from the photoluminescence spectrum (Fig. 1) of the grown wafer [8]. The accurate amount of In incorporated into the quantum well is difficult to state, however. The GRINSCH-SQW-STL structure is shown in Fig. 2.

After MBE growth, mesas were chemically etched on the wafer and the width of the active layer was $2 \mu \mathrm{m}$. The 


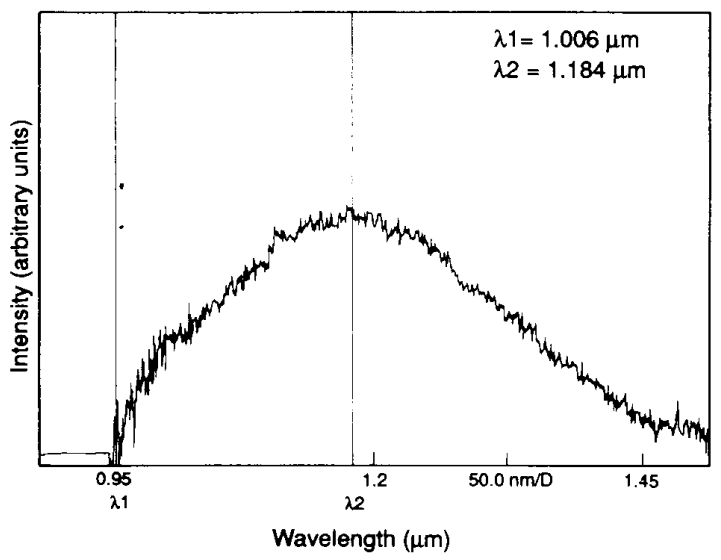

Fig. 1. Photoluminescence spectrum of an MBE grown InGaAs strained layer single-quantum-well wafer.

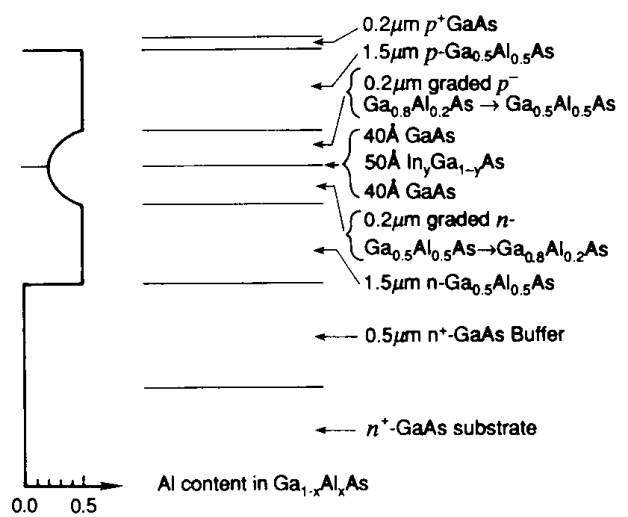

Fig. 2. A schematic of the GRINSCH-SQW-STL InGaAs material

wafer was then cleaned and the top GaAs cap layer was removed immediately prior to loading the wafer into an LPE system for regrowth. The regrowth temperature was $800^{\circ} \mathrm{C}$. A p- $\mathrm{Al}_{0.4} \mathrm{Ga}_{0.6}$ As layer and an $\mathrm{n}-\mathrm{Al}_{0.4} \mathrm{Ga}_{0.6} \mathrm{As}$ layer were grown successively to form a blocking junction.

After the second regrowth, the wafer was processed into BH lasers, using conventional fabrication techniques. The processes include thermal deposition of $\mathrm{SiO}_{2}$, photolithography for a stripe contact opening, shallow $\mathrm{Zn}$-diffusion, contact metalization, and annealing. The $\mathrm{Zn}$-diffusion is an important step to improve the ohmic contact and reduce contact resistance as we do not have a heavilydoped GaAs cap layer on the top of the device. A schematic of the finished device is shown in Fig. 3.

\section{Performance of the Lasers}

\section{A. Threshold, Spectrum and Far Field}

To test the performance of the lasers, the wafer was subsequently cleaved into laser bars of various cavity lengths. The laser chips were mounted on $\mathrm{Cu}$ blocks for $\mathrm{CW}$ operation. Light versus current $(L-I)$ characteristics were measured under CW conditions and very low threshold currents were observed. Some of the measured thresh-

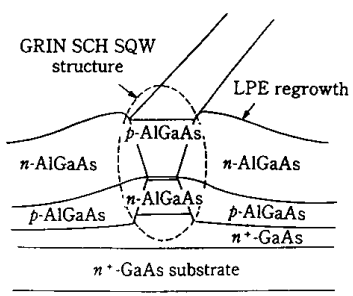

Fig. 3. A schematic structure of the $\mathrm{BH}$ InGaAs-GaAs laser.

TABLE I

Measured Threshold Current $I_{\text {th }}$ And External Quantum EFFICIENCY $\eta_{d}$ OF THE InGaAs-GaAs LASERS With DIFFERENT CAVITy LENGTHS $L$

\begin{tabular}{|c|c|c|c|}
\hline \hline $\mathrm{L}(\mu \mathrm{m})$ & $\mathrm{I} \operatorname{th}(\mathrm{mA})$ & $J \operatorname{th}\left(\mathrm{A} / \mathrm{cm}^{2}\right)$ & $\eta_{d}(\mathrm{~m} \mathrm{~W} / \mathrm{mA})$ \\
\hline 3976 & 9.5 & 121 & 0.19 \\
\hline 2385 & 6.5 & 136 & 0.25 \\
\hline 1676 & 5.8 & 173 & 0.34 \\
\hline 1590 & 5.6 & 176 & 0.36 \\
\hline 1004 & 4.2 & 209 & 0.33 \\
\hline 923 & 4.0 & 217 & 0.40 \\
\hline 613 & 3.7 & 302 & 0.43 \\
\hline 425 & 2.4 & 294 & 0.41 \\
\hline 304 & 2.8 & 461 & 0.35 \\
\hline 289 & 3.4 & 588 & 0.52 \\
\hline 198 & 3.8 & 960 & 0.37 \\
\hline 154 & 6.7 & 2175 & 0.27 \\
\hline 117 & 8.5 & 3632 & 0.28 \\
\hline
\end{tabular}

old currents $\left(I_{\text {th }}\right)$ along with their respective cavity lengths $(L)$ are listed in Table I. It can be seen from the table that the lowest threshold current obtained is $2.4 \mathrm{~mA}$ for a laser of cavity length $425 \mu \mathrm{m}$. To the best of our knowledge, this is the lowest figure ever reported to date for this material system and is also among the best results for uncoated semiconductor lasers. The lowest threshold current density was $120 \mathrm{~A} / \mathrm{cm}^{2}$ for a $3976 \mu \mathrm{m}$ long laser. Considering that this value is deduced from a $\mathrm{BH}$ laser, which may introduce additional carrier and optical losses comparing with broad area lasers, we expected even lower threshold current densities for broad area lasers. Indeed, a threshold current density of $114 \mathrm{~mA} / \mathrm{cm}^{2}$ was measured for $\mathrm{a} \sim 1540 \mu \mathrm{m}$ long, $100 \mu \mathrm{m}$ wide broad contact GRINSCH-SQW-STL laser.

The lasing wavelength for the uncoated device is about $0.93 \mu \mathrm{m}$ (for a cavity length of $\approx 250 \mu \mathrm{m}$ ). Photographs of the spectra are shown in Fig. 4. The spectra shown were obtained from the same laser with different mirror reflectivities. The reason for the lasing wavelength shift will be discussed later in Section IV-C. The lasing wavelength also depends on the cavity length. It becomes longer for longer cavity length. For a $1540 \mu \mathrm{m}$ long broadarea laser, a lasing wavelength of $0.99 \mu \mathrm{m}$ was measured. The laser is capable of delivering an optical power in excess of $80 \mathrm{~mW}$ under pulsed operation (for a laser of 1676 $\mu \mathrm{m}$ cavity length). The $L-I$ curve of this laser is shown in Fig. 5. 


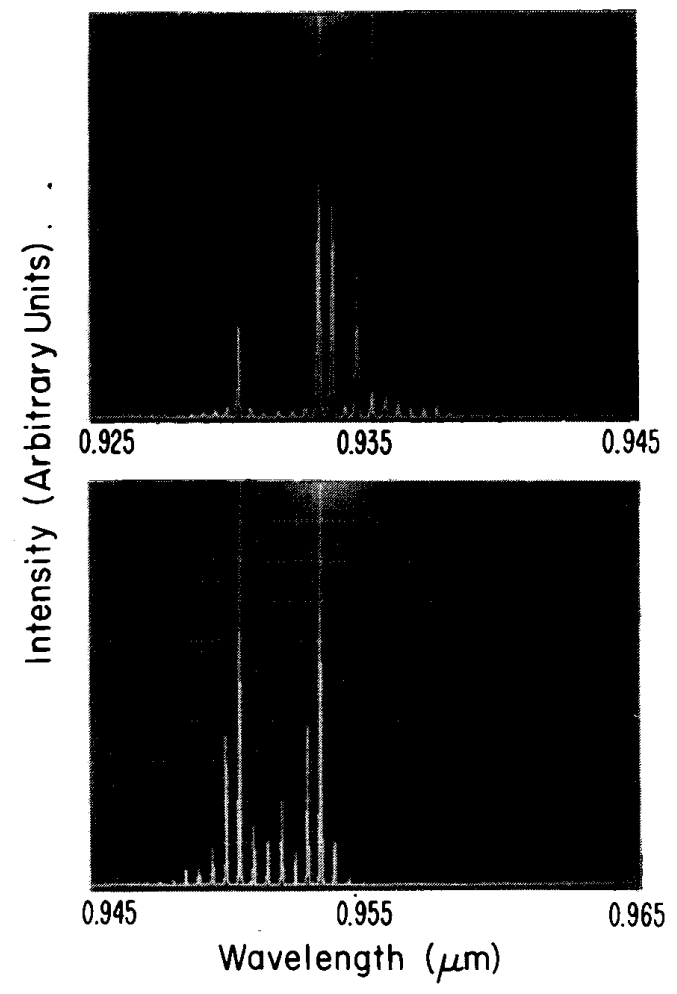

Fig. 4. Emission spectra of InGaAs-GaAs laser $(L=250 \mu \mathrm{m}$, signal power level is about $5 \mathrm{~mW}$ ). Top: for mirror reflectivity $R_{1}=R_{2} \approx 0.3$. Bottom: for mirror reflectivity $R_{1}=0.3, R_{2}=0.9$.

The lasers are found to operate in fundamental transverse mode, and a far-field pattern parallel to the junction plane is shown in Fig. 6. The beam divergence, full width at half maximum (FWHM), is about $18^{\circ}$.

In Fig. 7, a histogram of over 80 lasers, showing the dependence of threshold currents on cavity lengths, is presented. The threshold current of the laser decreases with cavity length for $L \geq 1 \mathrm{~mm}$ up to the longest laser, $L=4 \mathrm{~mm}$, measured, and is substantially a constant over the range $300 \mu \mathrm{m} \leq L \leq 1000 \mu \mathrm{m}(1 \mathrm{~mm})$, then increases steeply with further decrease of the cavity length. The observed increase at small cavity lengths is mainly related to the gain saturation behavior of single-quantum-well structure. The observed cavity length dependence of the threshold current is consistent with the theoretical result [18]

$$
J_{\text {th }}=J_{0} \exp \left[\frac{\alpha_{i}+\frac{1}{L} \ln \frac{1}{R}}{\Gamma G_{0}}\right]
$$

or

$$
I_{\mathrm{th}}=J_{\mathrm{th}} W L=J_{0} W L \exp \left[\frac{\alpha_{i}+\frac{1}{L} \ln \frac{1}{R}}{\Gamma G_{0}}\right]
$$

where $J_{\text {th }}$ is the threshold current density, $J_{0}$ is the transparency current density, $\alpha_{i}$ is the internal optical loss fac.

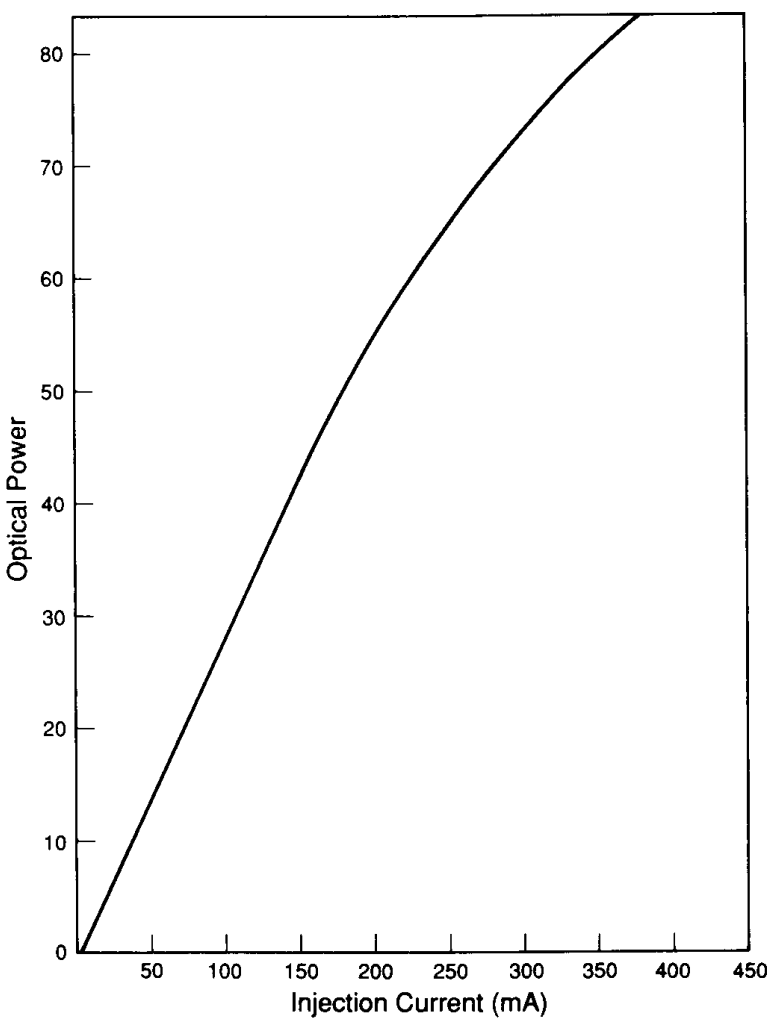

Fig. 5. $L-I$ characteristic of an InGaAs-GaAs SQW laser, showing an output power of $80 \mathrm{~mW}$.

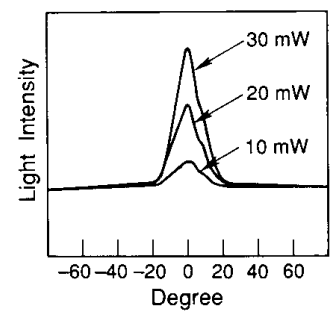

Fig. 6. A typical far-field pattern of an InGaAs-GaAs laser at different power level, showing stable single-transverse-mode operation.

tor, $R_{1}=R_{2}=R$ are mirror reflectivities, $L$ is the cavity length, $W$ is the active layer width, $\Gamma$ is the optical confinement factor, and $G_{0}$ is the gain constant. Equation (2) shows that the threshold currents should increase with decreasing cavity length for very short lasers. A theoretical $I_{\text {th }}-L$ curve with $J_{0}=120 \mathrm{~A} / \mathrm{cm}^{2}, \Gamma G_{0}=30 \mathrm{~cm}^{-1}, R$ $=0.3$ is also shown in Fig. 7. The experimental data follow the general trend of the theoretical curve fairly well, although the measured threshold currents seem somewhat higher than the calculated values.

\section{B. $\eta_{d}-L$ Relation}

The external quantum efficiency of the $\mathrm{BH}$ InGaAsGaAs SQW laser was measured under $\mathrm{CW}$ conditions. The best results obtained so far are $0.47 \mathrm{~mW} / \mathrm{mA}$ per facet 


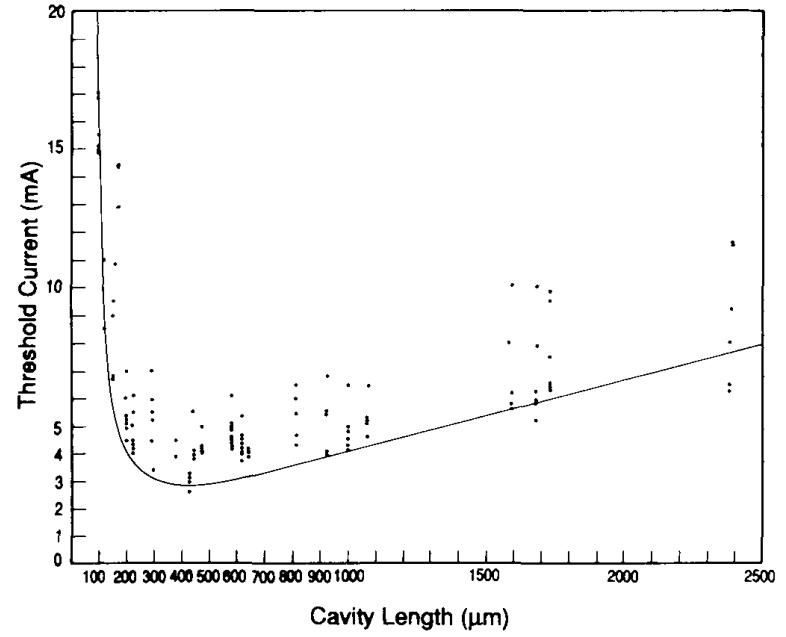

Fig. 7. The distribution of threshold currents against cavity lengths and a theoretical $I_{\mathrm{th}}-L$ curve with $J_{0}=120 \mathrm{~A} / \mathrm{cm}^{2}, \Gamma G_{0}=30 \mathrm{~cm}^{-1}, \alpha_{i}=3$ $\mathrm{cm}^{-1}, R=0.3$.

(or $35 \%$ per facet) for a laser of $587 \mu \mathrm{m}$ cavity length, and $0.52 \mathrm{~mW} / \mathrm{mA}(\approx 39 \%$ ) per facet for a $289 \mu \mathrm{m}$ long laser. The external quantum efficiency $\eta_{d}$ of the laser was a function of cavity length $L$. When the cavity length decreases, $\eta_{d}$ first increases similar to the case for conventional (nonquantum-well) semiconductor laser. However, at some point, $\eta_{d}$ reaches its maximum and then decreases rapidly with further decrease of the cavity length. The measured values of $\eta_{d}$ for lasers of various cavity lengths are shown in Fig. 8. Some experimental data are also listed in Table I. The rapid decrease of the external quantum efficiency at short cavity length is not predicted by the conventional semiconductor laser theory. The underlying physics is similar to that described in the previous paragraph. In short cavity lasers, the requirement for higher threshold gain causes a rapid increase in threshold carrier density. This, in turn, increases various kind of nonradiative recombination process such as Auger recombination [19], $L$-valley recombination [20], and carrier leakage over the heterostructure barrier [21] resulting in a decrease of the internal quantum efficiency $\eta_{i}$. In addition, the increased threshold current in very short cavity lasers results in a higher operation voltage which increases the leakage currents (e.g., the leakage current through the reverse biased blocking junction), causing a further decrease of the internal quantum efficiency.

\section{Internal Loss Factor $\alpha_{i}$ and Internal Quantum Efficiency $\eta_{i}$}

It is evident from Table I, Fig. 7, and Fig. 8 that the lasing threshold current and the external quantum efficiency display a weak dependence on the cavity length when the latter varies from $\sim 300 \mu \mathrm{m}$ to $\sim 1 \mathrm{~mm}$, indicating a very low internal loss of the lasers. It is thus interesting to determine the internal loss factor $\alpha_{i}$ and the internal quantum efficiency $\eta_{i}$.

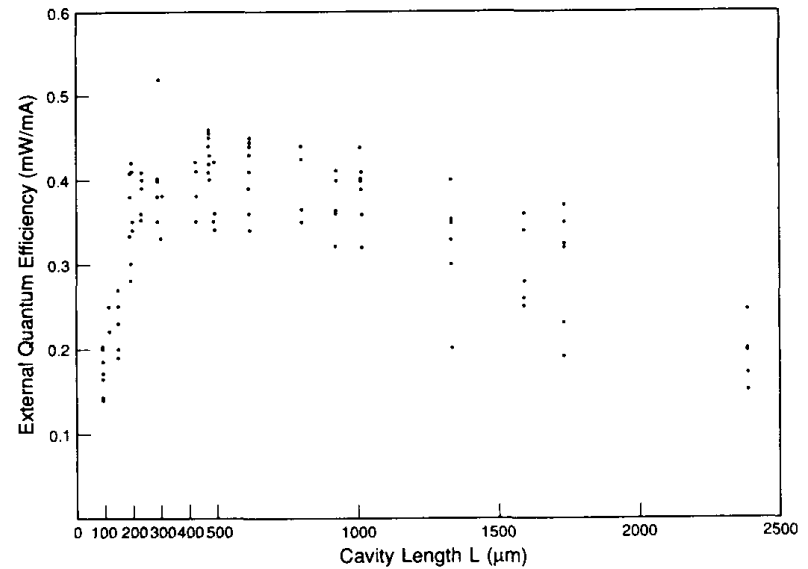

Fig. 8. External quantum efficiency as a function of cavity length.

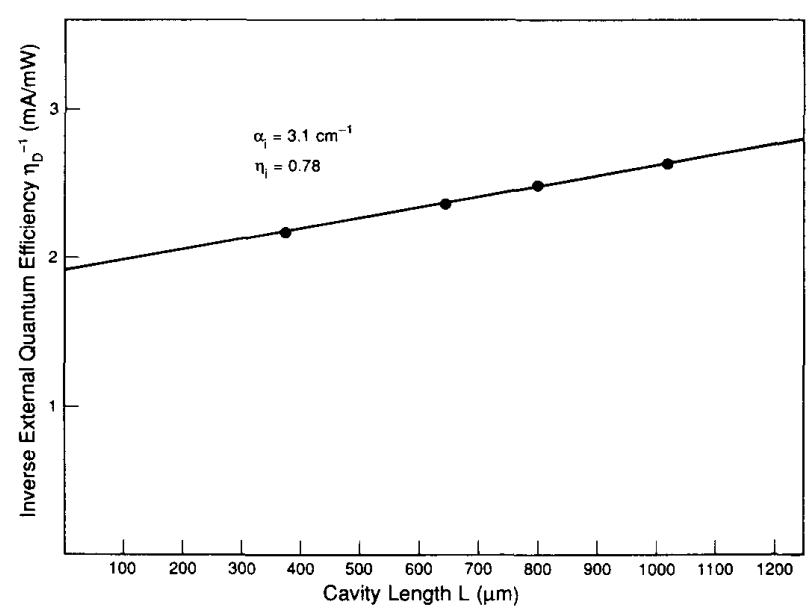

Fig. 9. An experimental plot of $\eta_{d}^{-1}$ versus $L$, showing $\alpha_{i}=3.1 \mathrm{~cm}^{-1}$ and $\eta_{i}=0.78$

The standard technique for experimental determination of $\eta_{i}$ and $\alpha_{i}$ utilizes the linear relation between $1 / \eta_{d}$ and $L$ [22]. However, for our SQW lasers, this relation does not hold for short cavity lasers as described previously. We measured $1 / \eta_{d}-L$ dependence for lasers subsequently cleaved from the same stripe and found that the linear relation was followed pretty well for $L>300 \mu \mathrm{m} . \alpha_{i}$ and $\eta_{i}$ were measured this way for lasers from different stripes. The values of $\alpha_{i}$ were found in the range of $3-10 \mathrm{~cm}^{-1}$, and $\eta_{i}$ 's were $60-80 \%$.

It should be noted that the $\alpha_{i}$ and $\eta_{i}$ were measured in a realistic laser structure. The internal loss $\alpha_{i}$ includes the free carrier absorption which should be very small (1-2 $\mathrm{cm}^{-1}$ ) in a SQW structure due to low optical confinement, the absorption in the cladding layers and the waveguide scattering loss. $\eta_{i}$ is governed by various kinds of leakage currents and nonradiative recombination processes. The measured $\alpha_{i}$ and $\eta_{i}$ showed the high quality of the material as well as the device. A $1 / \eta_{d}-L$ curve showing $\alpha_{i} \approx 3.1$ $\mathrm{cm}^{-1}$ and $\eta_{i} \approx 0.78$ is presented in Fig. 9 . 


\section{Laser Performance and Mirror REFLECTIVITIES}

\section{A. Coating and $I_{\mathrm{th}}$}

The very low internal loss of the laser results in a weak dependence of the threshold current and the external quantum efficiency on laser cavity length. It also suggests that for standard ( $\sim 250 \mu \mathrm{m})$ and short cavity lasers the uncoated mirror loss be dominant over the internal loss. One can then expect a substantial reduction in lasing threshold current with reduced mirror losses. In fact, the threshold modal gain $g_{\text {th }}$ of a semiconductor laser can be written as

$$
g_{\mathrm{th}}=\alpha_{i}+\frac{1}{2 L} \ln \frac{1}{R_{1} R_{2}}
$$

where $R_{1}$ and $R_{2}$ are mirror reflectivities. Shown in Table II is a comparison of the loss terms on the right-hand side of (3) for various cavity lengths and mirror reflectivities. It is clear that for our InGaAs-GaAs lasers, with uncoated mirrors ( $R_{1}=R_{2} \approx 0.3$ ), even for cavity lengths as large as $1000 \mu \mathrm{m}$, the mirror loss is still larger than the internal propagation loss. Also seen is for $L=250 \mu \mathrm{m}$ and $\alpha_{i}=$ $3 \mathrm{~cm}^{-1}, R_{1}$ and $R_{2}$ must be higher than 0.95 in order for the threshold to be dominated by the internal loss. The conclusion is that due to the very low internal loss, highreflectivity coating will reduce the threshold current substantially even in long cavity lasers. However, in order to take full advantage of the low loss to reach ultralow threshold, short cavity lasers are preferable ( $L<100 \mu \mathrm{m}$, e.g., ). In this case, the mirror reflectivities of $R>0.95$ or even higher should be used.

Different coatings were applied to lasers with different lengths. In all cases, high reflectivity coatings led to a reduction of the threshold current. Some of the typical results are listed in Table III. The $L-I$ curves for laser \#3 are presented in Fig. 10. The laser was $198 \mu \mathrm{m}$ long. The threshold current was $3.8 \mathrm{~mA}$ with uncoated facets. After the mirrors were coated to $R \approx 0.9$, a threshold current as low as $0.75 \mathrm{~mA}$ was obtained.

\section{B. Coating and External Quantum Efficiency}

A very important consequence of the low internal loss is a weak dependence of the external quantum efficiency on the mirror reflectivities. For different $\alpha_{i}$ values, the dependence of $\eta_{d}$ on $R\left(=R_{1}=R_{2}\right)$ with constant $\eta_{i}$ is depicted in Fig. 11. It is clear that for larger $\alpha_{i} L$, e.g., $\alpha_{i}$ $\approx 40 \mathrm{~cm}^{-1}$ and $L \approx 200 \mu \mathrm{m}, \eta_{d}$ drops very fast when the mirror reflectivity increases. However, for small $\alpha_{i} L, \eta_{d}$ does not change considerably even when $R$ increases from 0.3 to 0.9 . Therefore, the very low internal loss of the InGaAs-GaAs laser makes it possible to produce submilliamp lasers by using high-reflectivity coating and at the same time to maintain reasonably-high external quantum efficiencies and appreciable output powers.

The experimental data are consistent with the calculated results depicted in Fig. 11. Some of the measured $\eta_{d}$ for lasers with different coatings are presented in Table III.
TABLE II

A Comparison of the Internal Propagation Loss $\alpha_{i}$ And the Distributed Mirror Loss $(1 / 2 L)$ In $\left(1 / R_{1} R_{2}\right)$ FOR Different Mirror REFLECTIVITIES AND CAVITY LENGTHS

\begin{tabular}{|c|c|c|c|c|c|}
\hline \multirow{2}{*}{$L(\mu m)$} & \multirow{2}{*}{$\alpha_{i}\left(\mathrm{~cm}^{-1}\right)$} & \multicolumn{4}{|c|}{$\frac{1}{2 \mathrm{~L}} \ln \frac{1}{\mathrm{R}_{1} \mathrm{R}_{2}}\left(\mathrm{~cm}^{-1}\right)$} \\
\hline & & $R_{1}=R_{2}=0.3$ & $\mathbf{R}_{\mathbf{1}}=\mathbf{R}_{2}=0.7$ & $\mathbf{R}_{1}=\mathbf{R}_{2}=0.9$ & $\mathrm{R}_{1}=\mathrm{R}_{2}=0.95$ \\
\hline \multirow{2}{*}{1000} & 6 & \multirow{2}{*}{12.0} & \multirow{2}{*}{3.57} & \multirow{2}{*}{1.05} & \multirow{2}{*}{0.51} \\
\hline & 3 & & & & \\
\hline \multirow[b]{2}{*}{500} & 6 & \multirow[b]{2}{*}{24.0} & \multirow[b]{2}{*}{7.13} & \multirow{2}{*}{2.10} & \multirow[b]{2}{*}{1.02} \\
\hline & 3 & & & & \\
\hline \multirow[b]{2}{*}{250} & 6 & \multirow[b]{2}{*}{48.0} & \multirow[b]{2}{*}{14.3} & \multirow[b]{2}{*}{4.21} & \multirow[b]{2}{*}{2.05} \\
\hline & 3 & & & & \\
\hline \multirow[b]{2}{*}{100} & 6 & \multirow[b]{2}{*}{120} & \multirow[b]{2}{*}{35.7} & \multirow[b]{2}{*}{10.5} & \multirow[b]{2}{*}{5.13} \\
\hline & 3 & & & & \\
\hline \multirow[b]{2}{*}{50} & 6 & \multirow[b]{2}{*}{240} & \multirow[b]{2}{*}{71.4} & \multirow[b]{2}{*}{21.1} & \multirow[b]{2}{*}{10.3} \\
\hline & 3 & & & & \\
\hline
\end{tabular}

TABLE III

Measured Threshold Current $I_{\mathrm{th}}$, External Quantum Efficiency $\eta$ and Wavelength $\lambda$ as a Function of Mirror Reflectivities $R_{1}, R_{2}$ AND CAVITY LENGTH $L$

\begin{tabular}{|c|c|c|c|c|c|c|}
\hline Laser & $L(\mu \mathrm{m})$ & $R:$ & $\mathrm{R}_{2}$ & $\operatorname{Ith}(m A)$ & $\eta(\mathrm{mW} / \mathrm{mA})$ & $\lambda(\mu m)$ \\
\hline \multirow[b]{2}{*}{1} & \multirow{2}{*}{425} & 0.3 & 0.3 & 2.4 & 0.41 & \\
\hline & & 0.8 & 0.8 & 1.0 & 0.22 & \\
\hline \multirow{2}{*}{2} & \multirow{2}{*}{200} & 0.3 & 0.3 & 4.2 & & \\
\hline & & 0.7 & 0.9 & 1.2 & & \\
\hline \multirow{3}{*}{3} & \multirow{3}{*}{198} & 0.3 & 0.3 & 3.8 & 0.37 & 0.925 \\
\hline & & 0.9 & 0.3 & 2.3 & 0.71 & 0.947 \\
\hline & & 0.9 & 0.92 & 0.75 & 0.15 & 0.967 \\
\hline \multirow{3}{*}{4} & \multirow{3}{*}{198} & 0.3 & 0.3 & 4.1 & & \\
\hline & & 0.9 & 0.3 & 2.1 & & \\
\hline & & 0.9 & 0.92 & 0.8 & & \\
\hline \multirow{3}{*}{5} & \multirow{3}{*}{200} & 0.3 & 0.3 & 6 & 0.39 & 0.921 \\
\hline & & 0.8 & 0.3 & 3 & 0.71 & 0.945 \\
\hline & & 0.8 & 0.8 & 1.3 & 0.23 & 0.961 \\
\hline \multirow{3}{*}{6} & \multirow{3}{*}{150} & 0.3 & 0.3 & 10 & 0.27 & 0.903 \\
\hline & & 0.3 & 0.9 & 3.7 & 0.61 & 0.926 \\
\hline & & 0.9 & 0.9 & 3.3 & 0.12 & 0.951 \\
\hline \multirow{2}{*}{7} & \multirow{2}{*}{117} & 0.3 & 0.3 & 8.5 & & \\
\hline & & 0.8 & 0.8 & 1.1 & & \\
\hline \multirow{3}{*}{8} & \multirow{3}{*}{98} & 0.3 & 0.3 & 18 & & \\
\hline & & 0.3 & 0.8 & 5.9 & & \\
\hline & & 0.8 & 0.8 & 2.1 & & \\
\hline
\end{tabular}

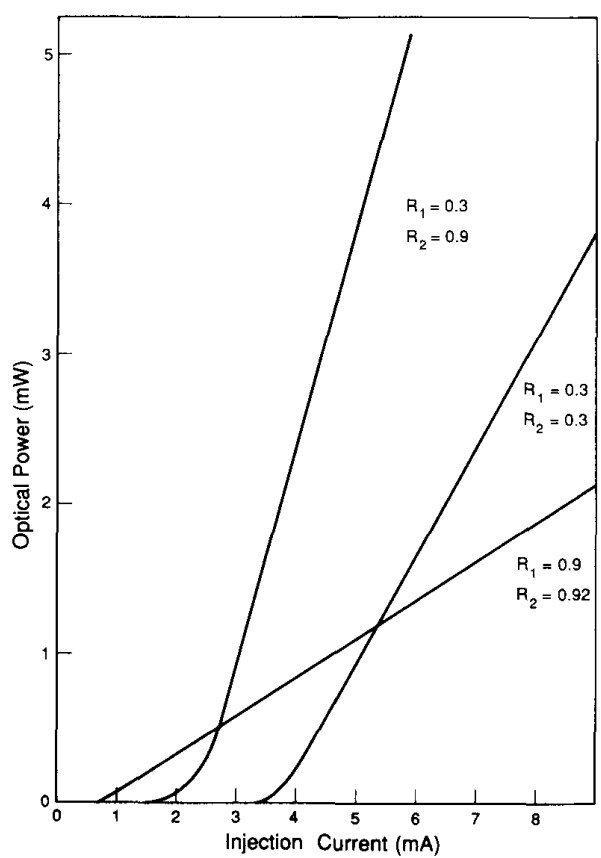

Fig. 10. $L-I$ characteristic of a low threshold InGaAs-GaAs laser ( $L=$ $198 \mu \mathrm{m}$ ) with different mirror reflectivities $R_{1}, R_{2}$. 


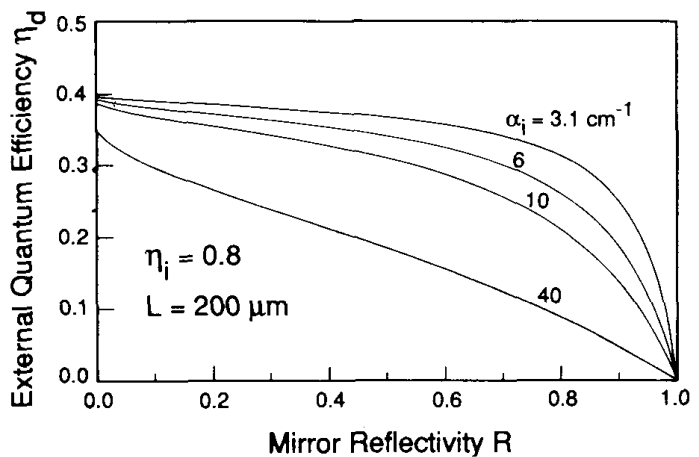

Fig. 11. External quantum efficiency with constant $\eta_{i}$ as a function of mirror reflectivity $R_{1}=R_{2}=R$ for different internal loss $\alpha_{i}$ values.

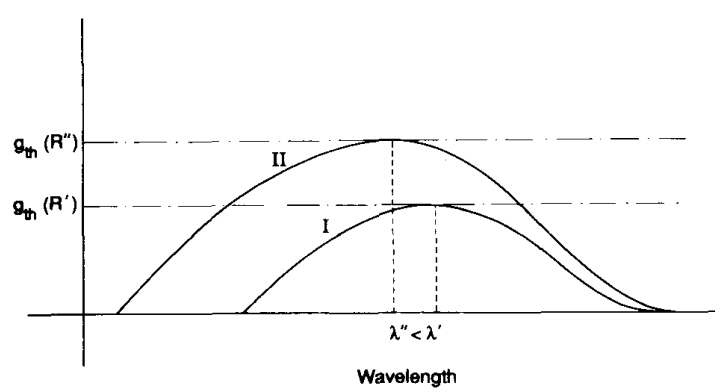

Fig. 12. Schematic gain spectra at threshold for different mirror reflectivities, showing different lasing wavelengths.

\section{Lasing Wavelengths as a Function of Mirror Reflectivities}

The control of mirror reflectivity has been found to be an effective way to tune the lasing wavelength of semiconductor lasers [23]. The physical mechanism for wavelength tuning by mirror coating is as follows. Facet coatings determine the effective distributed mirror loss $1 / L \ln$ $1 / R$ of the laser and thus the threshold modal gain [see (3)]. In semiconductor lasers, the gain spectrum has a nonsymmetric feature. Shown in Fig. 12 are two gain spectra at threshold corresponding to different mirror reflectivities $R^{\prime}>R^{\prime \prime}$. The threshold gain $g_{\text {th }}\left(R^{\prime}\right)$ is smaller than $g_{\text {th }}\left(R^{\prime \prime}\right)$. Therefore the corresponding lasing wavelength $\lambda^{\prime}$ is longer than $\lambda^{\prime \prime}$. It is obvious that the change in threshold gain and thus the lasing wavelength will be more pronounced if the internal loss $\alpha_{i}$ is smaller, assuming the same amount of change in mirror reflectivities. This is exactly the case in the present InGaAs-GaAs lasers. Some of the measured wavelengths of lasers with different coatings can be found in Table III. It was noted that by changing the mirrors' reflectivity $R$ from 0.3 to 0.9 , lasing wavelength was changed from $\sim 0.92$ to $\sim 0.96 \mu \mathrm{m}(\Delta \lambda \approx 400 \AA)$. This variation is much more pronounced than in conventional InP lasers $(\Delta \lambda \approx$ $150 \AA$ ) [23].

\section{Direct Current Modulation}

A direct current modulation was performed on a laser with both facets coated to $R \approx 0.8$. The threshold current of the laser was $1.3 \mathrm{~mA}$. The cavity length was $200 \mu \mathrm{m}$. To facilitate high-frequency operation, a $10 \mu \mathrm{m}$ wide mesa was etched around the active region to reduce the parasitic effect. When the laser was biased to $1 \mathrm{~mA}$ above threshold, a corner frequency of $1.8 \mathrm{GHz}$ and a $3 \mathrm{~dB}$ bandwidth of $\sim 2.8 \mathrm{GHz}$ was measured as shown in Fig. 13(a). The output power of the laser at this bias current was $\sim 0.2$ $\mathrm{mW}$. For this laser, a $3 \mathrm{~dB}$ bandwidth of $5.5 \mathrm{GHz}$ was measured at a bias current of $6.3 \mathrm{~mA}$. For another laser ( $I_{\mathrm{th}} \approx 1.5 \mathrm{~mA}$ ), at a bias current of $14 \mathrm{~mA}$, a $3 \mathrm{~dB}$ bandwidth of $7.6 \mathrm{GHz}$ was observed.

The modulation experiments showed that the strained layer InGaAs-GaAs lasers are indeed fast, especially at injection levels slightly above threshold. Although the speed of the laser is at least comparable with the reported results for its AlGaAs-GaAs counterpart [24], no significant enhancement of the modulation bandwidth has been observed. The limited maximum bandwidth in our experiment is believed to be caused by the parasitic capacitance. Further work is needed before we can properly compare the experimental results with the theoretical prediction.

\section{CONCLUSION}

In conclusion, strained layer InGaAs-GaAs GRINSCH SQW lasers were fabricated by a hybrid MBE and LPE techniques. Very low threshold currents, $2.4 \mathrm{~mA}$ for the uncoated laser $(L=425 \mu \mathrm{m})$ and $0.75 \mathrm{~mA}$ for the coated laser ( $L=198 \mu \mathrm{m})$, were obtained. The lasing wavelength was $\sim 0.93 \mu \mathrm{m}$ for uncoated lasers. External quantum efficiency as high as $0.52 \mathrm{~mW} / \mathrm{mA}$ per facet $(L-300 \mu \mathrm{m})$ and an output power of over $80 \mathrm{~mW}$ ( $L=1.68 \mathrm{~mm}$ ) were observed. A modulation bandwidth of $7.6 \mathrm{GHz}$ was demonstrated at low bias current. The very low internal loss of the laser results in a weak dependence of $I_{\mathrm{th}}$ and $\eta_{d}$ on the cavity length (for not very short cavity lasers) and a weak dependence of $\eta_{d}$ and output power on the mirror reflectivity. It also offers an effective way to tune the threshold current and lasting wavelength by facet coating. Because of these features this laser is attractive for applications which require a combination of low threshold, high speed, high quantum efficiency, and reasonable output powers.

\section{ACKNOWLEDGMENT}

T. R. Chen would like to thank J. Paslaski for helpful discussions on high-frequency modulation. The authors are also grateful to D. Armstrong for his help in many ways during the LPE growth process.

\section{REFERENCES}

[1] M. D. Camras, J. M. Brown, N. Holonyak, Jr., M. A. Nixon, R. W. Kaliski, M. J. Ludowise, W. T. Dietze, and C. R. Lewis, 


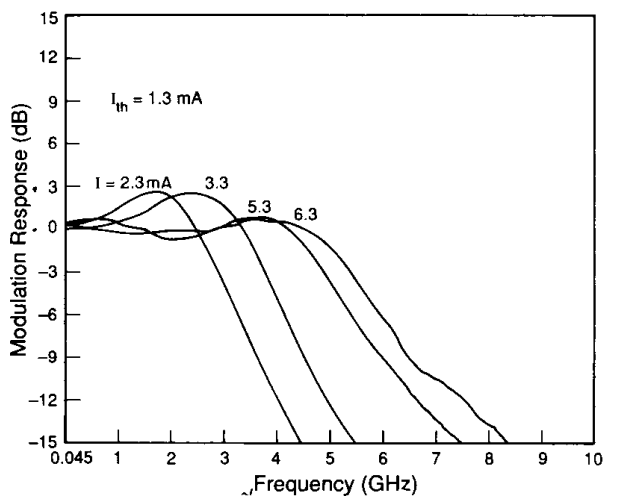

(a)

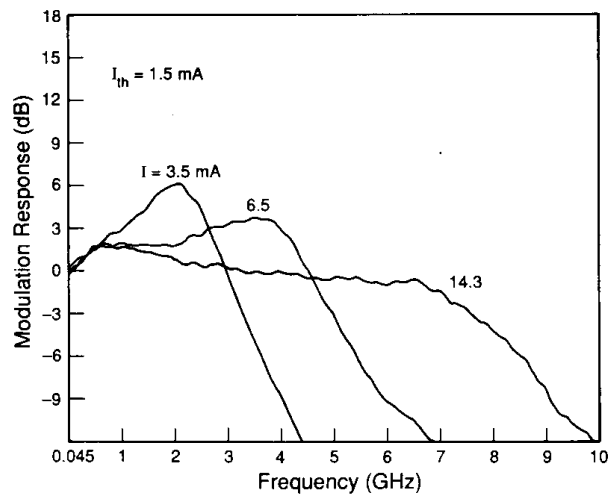

(b)

Fig. 13(a). Frequency response of a low threshold InGaAs-GaAs laser, showing corner frequency $f_{c}=1.8 \mathrm{GHz}$ at a bias current $I=2.3 \mathrm{~mA}$. Cavity length $L=200 \mu \mathrm{m}$, threshold current $I_{\mathrm{th}}=1.3 \mathrm{~mA}$, and mirror reflectivities $R_{1}=R_{2}=0.8$. (b) Frequency response of a low threshold InGaAsGaAs laser, showing $3 \mathrm{~dB}$ bandwidth $f_{B}=7.6 \mathrm{GHz}$ at a bias current $I=14 \mathrm{~mA}$.

"Stimulated emission in strained-layer quantum well heterostructures," J. Appl. Phys., vol. 54, pp. 6183-6189, 1983.

[2] N. G. Anderson, Y. C. Lo, and R. M. Kolbas, "High-efficiency carrier collection and stimulated emission in thin ( $50 \AA$ ) pseudomorphic $\mathrm{In}_{x} \mathrm{Ga}_{1-x}$ As quantum wells," Appl. Phys. Lett., vol. 49, pp. 758$760,1986$.

[3] W. D. Laidig, P. J. Caldwell, Y. F. Lin, and C. K. Peng, "'Strainedlayer quantum-well injection laser," Appl. Phys.Lett., vol. 44, pp. $653-655,1984$

[4] W. D. Laidig, Y. F. Lin, and P. J. Caldwell, "Properties of In $_{x} \mathrm{Ga}_{1-x} \mathrm{As}$-GaAs strained-layer quantum-well-heterostructure injection lasers," J. Appl. Phys., vol. 57, pp. 33-38, 1985.

[5] D. Feketa, K. T. Chan, J. M. Ballantyne, and L. F. Eastman, "Graded-index separate-confinement InGaAs/GaAs strained-layer quantum well grown by metalorganic chemical vapor deposition," Appl. Phys. Lett., vol. 49, pp. 1659-1660, 1986.

[6] S. E. Fischer, D. Fekete, G. B. Feak, and J. M. Ballantyne, "Ridge waveguide injection laser with a GaInAs strained-layer quantum well $(\lambda=1 \mu \mathrm{m}), "$ Appl. Phys. Lett., vol. 50, pp. 714-716, 1987.

[7] Y. J. Yang, K. Y. Hsieh, and R. M. Kolbas, "Continuous roomtemperature operation of an InGaAs-GaAs-AlGaAs strained layer laser,' Appl. Phys. Lett., vol. 51, pp. 215-217, 1987.

[8] R. M. Kolbas, N. G. Anderson, W. D. Laidig, Y. Sin, Y. C. Hsieh, and $Y$. J. Yang, "Strained-layer InGaAs-GaAs-AlGaAs photopumped and current injection lasers," IEEE J. Quantum Electron., vol. 24, pp. 1605-1613, 1988.

[9] A. R. Adams, "Band-structure engineering for low-threshold highefficiency semiconductor lasers," Electron Lett., vol. 22, no. 5, pp. 249-250, 1986

[10] E. Yablonovitch and E. O. Kane, "Reduction of lasing threshold current density by lowering of valence band effective mass," J. Lightwave Technol., vol. LT-4, pp. 504-506, 1986.

[11] I. Suemune, L. A. Coldren, M. Yamanishi, and Y. Kan, "Extremely wide modulation bandwidth in a low threshold current strained quantum well laser," Appl. Phys. Lett., vol. 53, no. 15, pp. 1378-1380, 1988 .

[12] T. C. Chong and C. G. Fonstad, "Theoretical gain of strained-layer semiconductor lasers in the large strain regime," IEEE $J$. Ouantum Electron., vol. 25, pp. 171-178, 1989

[13] E. P. O'Reilly, "Valence band engineering is strained-layer structure," Semicond. Sci. Technol, vol. 4, pp. 121-137, 1989.

[14] S. D. Offsey, W. J. Schaff, P. J. Tasker, H. Ennen, and L. F. Eastman, "Strained-layer InGaAs-GaAs-AlGaAs graded-index separate confinement heterostructure single quantum well lasers grown by molecular beam epitaxy," Appl. Phys. Lett., vol. 54, pp. 2527-2529. 1989

[15] P. K. York, K. J. Beernink, G. E. Fernández, and J. J. Coldren, "InGaAs-GaAs stained layer quantum well buried heterostructure lasers $(\lambda>1 \mu \mathrm{m})$ by metalorganic chemical vapor deposition," Appl. Phys. Lett., vol. 54, pp. 499-501, 1989.
[16] W. Stutius, P. Gavrilovic, J. E. Williams, K. Meehan, and J. H Zarrabi, "Continuous operation of high-power $(200 \mathrm{~mW})$ stainedlayer $\mathrm{Ga}_{1-r} \mathrm{In}_{\mathrm{r}} \mathrm{As} / \mathrm{GaAs}$ quantum well lasers with emission wavelength: $0.87 \mu \mathrm{m} \leq \lambda \leq 0.95 \mu \mathrm{m}$,"' Electron. Lett., vol. 24 , no. 24 , pp. 1493-1494, 1988.

[17] S. E. Fischer, R. G. Waters, D. Fekete, J. M. Ballantyne, Y. C. Chen, and B. A. Saltz, "Long-lived InGaAs quantum well lasers," Appl. Phys. Lett., vol. 54, pp. 1861-1862, 1989.

[18] P. W. A. McIlroy, A. Kurobe, and Y. Uematsu, "Analysis application of theoretical gain curves to the design of multi-quantum-well lasers," IEEE J. Quantum Electron., vol. QE-21, pp. 1958-1963. 1985.

[19] R. I. Taylor, R. A. Abram, M. G. Burt, and C. Smith, "Auger re combination in a quantum-well-heterostructure laser," Proc. IEEE, vol. 132 , Pt. J, pp. $364-370,1985$.

[20] A. Sugimura, "Threshold currents for AlGaAs quantum well lasers," IEEE J. Ouantum Electron., vol. QE-20, pp. 336-343, 1984

[21] C. M. Wu and E. S. Yang, "Physical mechanisms of carrier leakage in DH injection lasers," J. Appl. Phys., vol. 49, pp. 3114-3117, 1978.

[22] H. C. Casey Jr. and M. B. Panish, Heterostructure Lasers, part A: Fundamental Principles, Orlando, FL: Academic Press, 1978.

[23] T. R. Chen, Y. H. Zhuang, P. L. Derry, and A. Yariv, "The application of dielectrical coating to semiconductor lasers," unpublished.

[24] P. L. Derry, T. R. Chen, Y. H. Zhuang, J. Paslaski, M. Mittelstein K. Vahala, A. Yariv, K. Y. Lau, N. Bar-Chaim, "Properties of ultra low threshold single quantum well (Al, Ga)As lasers for compute interconnects," Optoelectronics-Devices and Technol., vol. 3, no. 2 , pp. $117-130,1988$

T. R. Chen, photograph and biography not available at the time of publi cation.

L. Eng, photograph and biography not available at the time of publication.

B. Zhao, photograph and biography not available at the time of publication.

Y. H. Zhuang, photograph and biography not available at the time of publication.

S. Sanders, photograph and biography not available at the time of publication.

H. Morkoc (S'72-M'76-SM'79-F'87), photograph and biography not available at the time of publication. 


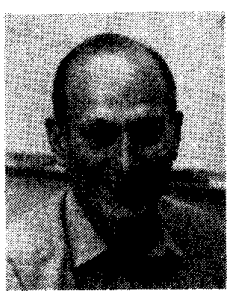

Amnon Yariv (S'56-M'59-F'70), a native of Israel, obtained the B.S., M.S., and Ph.D. degrees in electrical engineering from the University of California, Berkeley, in 1954, 1956, and 1958, respectively.

He joined Bell Telephone Laboratories, Murray $\mathrm{Hill}, \mathrm{NJ}$, in 1959 , at the early stages of the laser effort. He came to the California Institute of Technology, Pasadena, in 1964 as a Associate Professor of Electrical Engineering, becoming a Professor in 1966. In 1980 he become the Thomas G. Myers Professor of Electrical Engineering and Applied Physics. On the technical side, he took part (with various co-workers) in the discovery of a number of early solid-state laser systems, in proposing and demonstrating semiconductor based integrated optics technology, and in pioneering the field of phase conjugate optics. His present research efforts are in the areas of nonlinear optics, semiconductor lasers, and integrated optics. He has published widely in the laser and optics fields some 300 papers and has written a number of basic texts in quantum electronics, optics, and quantum mechanics. $\mathrm{He}$ is also a founder and chairman-of-the-board of the Ortel Corp., Alhambra, CA.

Dr. Yariv is a member of the American Physical Society, Phi Beta Kappa, the American Academy of Arts and Sciences, and the Nationa Academy of Engineering, and a Fellow of the Optical Society of America He received the 1980 Quantum Electronics Award of the IEEE, the 1985 University of Pennsylvania Pender Award, and the 1986 Optical Society of America Ives Medal. 